\title{
WILEY-VCH
}

\section{Scalable photocatalyst panels for photoreforming of plastic, biomass and mixed waste in flow}

\author{
Taylor Uekert, Mark A. Bajada, Teresa Schubert, Christian M. Pichler and Erwin Reisner* \\ Department of Chemistry, University of Cambridge, Lensfield Road, Cambridge CB2 1EW, UK \\ *Email: reisner@ch.cam.ac.uk \\ Website: http://www-reisner.ch.cam.ac.uk/
}

\begin{abstract}
Solar-driven reforming uses sunlight and a suitable photocatalyst to generate $\mathrm{H}_{2}$ fuel from waste at ambient temperature and pressure. However, it faces practical scaling challenges such as photocatalyst dispersion and recyclability, competing light absorption by the waste solution, slow reaction rates and low conversion yields. Here, the immobilization of a noblemetal-free carbon nitride/nickel phosphide $\left(\mathrm{CN}_{\mathrm{x}} \mid \mathrm{Ni}_{2} \mathrm{P}\right)$ photocatalyst on textured glass is shown to overcome several of these limitations. The $1 \mathrm{~cm}^{2} \mathrm{CN}_{\mathrm{x}} \mid \mathrm{Ni}_{2} \mathrm{P}$ panels photoreform plastic, biomass, food and mixed waste into $\mathrm{H}_{2}$ and organic molecules with rates comparable to those of photocatalyst slurries. Furthermore, the panels enable facile photocatalyst recycling and novel photoreactor configurations that prevent parasitic light absorption, thereby promoting $\mathrm{H}_{2}$ production from turbid waste solutions. Scalability is further verified by preparing $25 \mathrm{~cm}^{2}$ $\mathrm{CN}_{\mathrm{x}} \mid \mathrm{Ni}_{2} \mathrm{P}$ panels for use in a custom-designed flow reactor to generate up to $21 \mu \mathrm{mol}_{\mathrm{H}_{2}} \mathrm{~m}^{-2} \mathrm{~h}^{-1}$ under "real-world" (seawater, low sunlight) conditions. The application of inexpensive and readily scalable $\mathrm{CN}_{\mathrm{x}} \mid \mathrm{Ni}_{2} \mathrm{P}$ panels to photoreforming of a variety of real waste streams provides a crucial step towards the practical deployment of this technology.
\end{abstract}

Keywords: photocatalysis, photoreforming, waste, immobilization, scaling 


\section{WILEY-VCH}

\section{Introduction}

As nations across the world strive towards a carbon-neutral future powered by a circular economy, $\mathrm{H}_{2}$ has become a versatile option for decarbonizing the transport, energy storage, heating, chemical and steel industries. ${ }^{[1]}$ Photocatalytic $\mathrm{H}_{2}$ evolution, in which sunlight is used to split water into $\mathrm{H}_{2}$ and $\mathrm{O}_{2}$, is being pursued as a sustainable technology capable of reducing the 830 million metric tons of $\mathrm{CO}_{2}$ emissions ${ }^{[1]}$ currently associated with $\mathrm{H}_{2}$ generation by steam methane reforming. Several up-scaled photocatalytic systems of at least $1 \mathrm{~m}^{2}$ have been reported: ${ }^{[2-5]}$ the largest, a $103.7 \mathrm{~m}^{2}$ array of tracking concentrator reactors containing a NiS$\mathrm{Cd}_{x} \mathrm{Zn}_{1-\mathrm{x}} \mathrm{S}$ photocatalyst and $\mathrm{Na}_{2} \mathrm{SO}_{3}$ as a sacrificial electron donor, produced $10,400 \mu_{\mathrm{mol}_{H}}$ $\mathrm{m}^{-2} \mathrm{~h}^{-1}{ }^{[6]}$ However, scaling still faces several challenges including photocatalyst sedimentation and re-use, inefficient utilization of visible light, use of costly and unsustainable precious metals and sacrificial reagents, and, in the case of overall water splitting, separation of explosive $\mathrm{H}_{2} / \mathrm{O}_{2}$ mixtures.

Photoreforming (PR) offers an alternative $\mathrm{H}_{2}$ generation method that overcomes several of these scaling limitations. ${ }^{[7,8]}$ In PR, electrons in a photocatalyst are excited to the conduction band by sunlight and transferred to a co-catalyst, where they reduce water to $\mathrm{H}_{2}$. Holes in the valence band oxidize an oxygenated organic substrate into smaller molecules or $\mathrm{CO}_{2}$ (Figure 1). Substrates can include freely-available biomass, food or certain types of plastic waste, ${ }^{[8-12]}$ thereby removing the need for costly sacrificial reagents and simultaneously contributing to waste mitigation. Gas separation is also straightforward as $\mathrm{O}_{2}$ is not produced. Furthermore, PR is less energetically demanding than overall water splitting and can in principle proceed on various narrow band gap photocatalysts capable of absorbing a wide range of visible and even infrared light. ${ }^{[9]}$ Despite these various advantages, PR of real waste (polyester microfibers) has only been up-scaled in batch to an irradiation area of $60 \mathrm{~cm}^{2}$ with the photocatalyst in suspension, producing $76 \mu \mathrm{mol}_{\mathrm{H}_{2}} \mathrm{~m}^{-2} \mathrm{~h}^{-1}$. ${ }^{11]}$ This system faced several challenges, including 


\section{WILEY-VCH}

photocatalyst sedimentation during PR due to inefficient stirring, as well as competing light absorption and scattering from the waste particulates. In order to facilitate further scaling of this promising technology, reactor and overall system design must be improved.

Of the scalable reactors proposed for photocatalytic processes, flat panel reactors are a simple and inexpensive option consisting of a thin layer of reactant fluid sandwiched between an inclined surface and a window, and utilize a photocatalyst slurry or immobilized panel. ${ }^{[13]}$ Photocatalyst panels can prevent sedimentation and promote catalyst recycling, although these benefits often come at the cost of reduced mass transfer between the catalyst and reactant. ${ }^{[2,14]}$ Panels are of particular interest for PR as they could be applied to the reactor window, thereby preventing the obstructive effect of turbid waste solutions on photocatalyst light absorption. A range of different photocatalysts - including metal oxides, transition metal oxynitrides, and carbon nitride - have been affixed to panels by drop-casting or screen printing, and were utilized for $\mathrm{H}_{2}$ evolution both with ${ }^{[2]}$ and without ${ }^{[3,14-17]}$ sacrificial electron donors. A record areal efficiency of $271,000 \mu \mathrm{mol}_{\mathrm{H}_{2}} \mathrm{~m}^{-2} \mathrm{~h}^{-1}$ was achieved for overall water splitting on a $25 \mathrm{~cm}^{2}$ $\mathrm{RhCrO}_{\mathrm{x}} / \mathrm{SrTiO}_{3}: \mathrm{Al}$ panel, which was prepared on frosted glass by drop-casting with $\mathrm{SiO}_{2}$ as an inorganic binder. ${ }^{[3]}$ Nevertheless, photocatalyst panels that do not contain precious metal cocatalysts and are applicable to waste PR have yet to be demonstrated.

Here, we prepare intrinsically scalable panels by a facile drop-casting, low temperature method with a noble-metal-free carbon nitride/nickel phosphide $\left(\mathrm{CN}_{\mathrm{x}} \mid \mathrm{Ni}_{2} \mathrm{P}\right)$ photocatalyst (Figure 1). This material is of particular interest due to its visible light absorption (band gap of $2.7 \mathrm{eV}, \lambda<460 \mathrm{~nm}$ ), simple synthesis from inexpensive precursors, stability under $\mathrm{pH}$ conditions ranging from highly acidic to alkaline, and demonstrated applicability to slurrybased PR of plastic, food and mixed wastes. ${ }^{[11,12]}$ The $\mathrm{CN}_{\mathrm{x}} \mid \mathrm{Ni}_{2} \mathrm{P}$ panels are first optimized for maximal $\mathrm{H}_{2}$ production, light absorption and recyclability at a $1 \mathrm{~cm}^{2}$ scale. Up-scaled $25 \mathrm{~cm}^{2}$ panels are then applied to PR of cellulose, polyethylene terephthalate (PET) and municipal 
solid waste (MSW) in flow, where the irradiation configuration is shown to be crucial for enhancing $\mathrm{H}_{2}$ production in comparison to a photocatalyst slurry. The system is also shown to maintain up to $50 \%$ of its activity in seawater under reduced ( 0.2 sun) light, underlining its versatility even in demanding "real world" conditions.

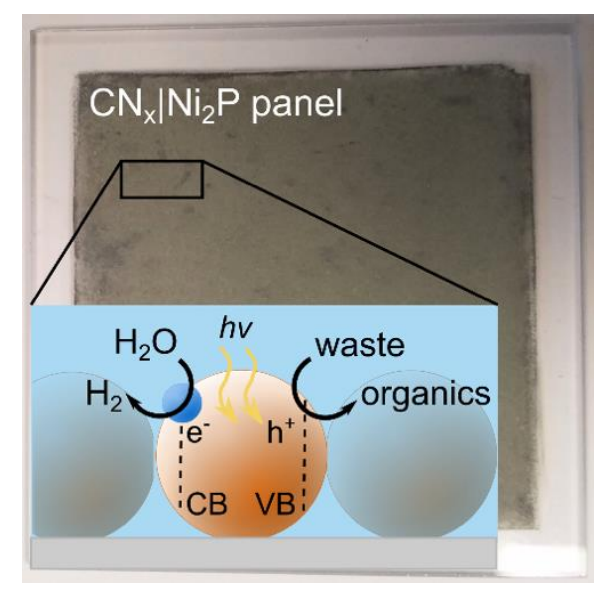

Figure 1. Photograph of a $25 \mathrm{~cm}^{2}$ carbon nitride/nickel phosphide $\left(\mathrm{CN}_{\mathrm{x}} \mid \mathrm{Ni}_{2} \mathrm{P}\right)$ panel with a schematic diagram of the photoreforming process $\left(\mathrm{CN}_{\mathrm{x}}\right.$ and $\mathrm{Ni}_{2} \mathrm{P}$ are represented by the orange and blue spheres, respectively).

\section{Results \& Discussion}

\subsection{Assembly, characterization and optimization of panels}

$\mathrm{CN}_{\mathrm{x}}$ was synthesized from melamine at $550{ }^{\circ} \mathrm{C}$ and loaded with a $\mathrm{Ni}_{2} \mathrm{P}$ nanoparticle co-catalyst $(2 \mathrm{wt} \%)$ as reported previously. ${ }^{[1,12]} \mathrm{Ni}_{2} \mathrm{P}$ was present in the expected quantity $\left(15.1 \mathrm{mg}_{\mathrm{Ni}}\right.$ $\mathrm{g}_{\mathrm{CNx}}{ }^{-1}, 5.8 \mathrm{mg}_{\mathrm{P}} \mathrm{g}_{\mathrm{CNx}}{ }^{-1}$ ) as determined by inductively coupled plasma optical emission spectroscopy (ICP-OES, Table S1), and the bulk chemical and optical properties of polymeric $\mathrm{CN}_{\mathrm{x}}$ were unaffected by co-catalyst addition, as characterized by UV-vis, Fourier transform infrared (FTIR) spectroscopy, powder X-ray diffraction, and X-ray photoelectron spectroscopy (Figure S1). A variety of catalyst immobilization procedures were studied, including different substrates (flat or frosted glass), deposition methods (spin-coating or drop-casting), solvents $\left(\mathrm{H}_{2} \mathrm{O}\right.$ or ethanol), binders (polyethylene glycol, nafion, or $\mathrm{SiO}_{2}$ nanoparticles or microparticles), and annealing conditions $\left(80-450{ }^{\circ} \mathrm{C}\right)$. After comparing $\mathrm{H}_{2}$ evolution activities and 
stability under both neutral and alkaline (up to $0.5 \mathrm{M}$ aq. $\mathrm{KOH}$ ) conditions, a simple, lowtemperature panel preparation method was selected for its maximal performance. In brief, $\mathrm{CN}_{\mathrm{x}} \mid \mathrm{Ni}_{2} \mathrm{P}$ was dispersed in ethanol $\left(20 \mathrm{mg} \mathrm{mL}^{-1}\right)$ using an ultrasonic probe, to which a commercial $\sim 5 \mathrm{wt} \%$ nafion solution ( $1 \mathrm{vol} \%$ of total) was added. Nafion is a fluoropolymercopolymer that is water permeable and chemically and photochemically resistant, making it an ideal binder for hydrophilic and stable panels. ${ }^{[18]}$ The photocatalyst mixture was then drop-cast onto clean frosted glass $\left(16 \mu \mathrm{L} \mathrm{cm}^{-2}\right)$ in multiple layers and annealed overnight at $80{ }^{\circ} \mathrm{C}$ in air.

The photocatalyst loading was varied by adjusting the number of applied layers (2-12 layers for loadings of $0.64-3.84 \mathrm{mg}_{\mathrm{CNx}} \mathrm{cm}^{-2}$ ). ICP-OES shows that the $\mathrm{Ni}$ and $\mathrm{P}$ content of the immobilized panels are slightly lower than predicted (Table S1), likely because less photocatalyst was drop-cast than calculated due to the non-homogeneous dispersion of $\mathrm{CN}_{\mathrm{x}} \mid \mathrm{Ni}_{2} \mathrm{P}$ in ethanol. The resulting $\mathrm{CN}_{\mathrm{x}} \mid \mathrm{Ni}_{2} \mathrm{P}$ panels $\left(1 \mathrm{~cm}^{2}\right)$ were optimized for maximal $\mathrm{H}_{2}$ evolution by immersion in $\mathrm{H}_{2} \mathrm{O}(2 \mathrm{~mL})$ containing ethylene glycol (EG, $\left.25 \mathrm{mg} \mathrm{mL}^{-1}\right)$ and exposure to simulated solar light $\left(100 \mathrm{~mW} \mathrm{~cm}^{-2}\right)$ at $25{ }^{\circ} \mathrm{C}$ under $\mathrm{N}_{2}$ atmosphere without stirring. EG was chosen as a "model" substrate as it is a monomer of PET, which comprises $10 \%$ of global plastic waste ${ }^{[19]}$ and is thus of interest for PR. All $\mathrm{H}_{2}$ evolution values are background-corrected by those without substrate, which accounts for $<12 \%$ of total $\mathrm{H}_{2}$ yield and can be potentially attributed to the decomposition of excess sodium hypophosphite from the co-catalyst synthesis ${ }^{[11]}$ or residual ethanol from the panel preparation procedure (Table $\mathrm{S} 2$ ). No $\mathrm{H}_{2}$ was detected without the photocatalyst or in the dark (Table S3).

$\mathrm{H}_{2}$ evolution increases relatively linearly for panels coated with 0.64 to $1.92 \mathrm{mg}_{\mathrm{CNx}} \mathrm{cm}^{-2}$, but plateaus at higher catalyst loadings (Figure 2a, Table S4). This correlates with diffuse reflectance UV-vis spectroscopy measurements, which show that light transmittance through the $\mathrm{CN}_{\mathrm{x}} \mid \mathrm{Ni}_{2} \mathrm{P}$ panels decreases in the characteristic $\mathrm{CN}_{\mathrm{x}}$ absorption range $(\lambda<450 \mathrm{~nm})$ with increasing catalyst loading until saturating at $1.92 \mathrm{mg}_{\mathrm{CNx}} \mathrm{cm}^{-2}$ (Figure 2b). The relatively low 


\section{WILEY-VCH}

transmittance at $\lambda>450 \mathrm{~nm}$ for all samples is due to scattering from the $\mathrm{Ni}_{2} \mathrm{P}$ co-catalyst, which is also observed for $\mathrm{CN}_{\mathrm{x}} \mid \mathrm{Ni}_{2} \mathrm{P}$ powder (Figure S1). The transmittance at $\lambda<450 \mathrm{~nm}$ does not drop below $\sim 16 \%$ due to light scatter losses from the uneven frosted glass surface. ${ }^{[20]}$ The saturation effect at high photocatalyst loadings is likely because the glass is already covered by a continuous photocatalyst layer at a concentration of $1.92 \mathrm{mg}_{\mathrm{CNx}} \mathrm{cm}^{-2}$ (Figure 2c). Additional layers increase the film thickness from $9.0 \mu \mathrm{m}$ to a maximum of $10.9 \mu \mathrm{m}$ (Figure $2 \mathbf{d}$, Figure S2) and slightly enhance light absorption, but will have little effect on $\mathrm{H}_{2}$ evolution as photocatalysis primarily occurs at the panel surface rather than in its bulk. The plateau in $\mathrm{H}_{2}$ evolution for photocatalyst slurries with concentrations greater than $2.56 \mathrm{mg}_{\mathrm{CNx}} \mathrm{cm}^{-2}$ can be similarly attributed to light absorption saturation (Figure S3).
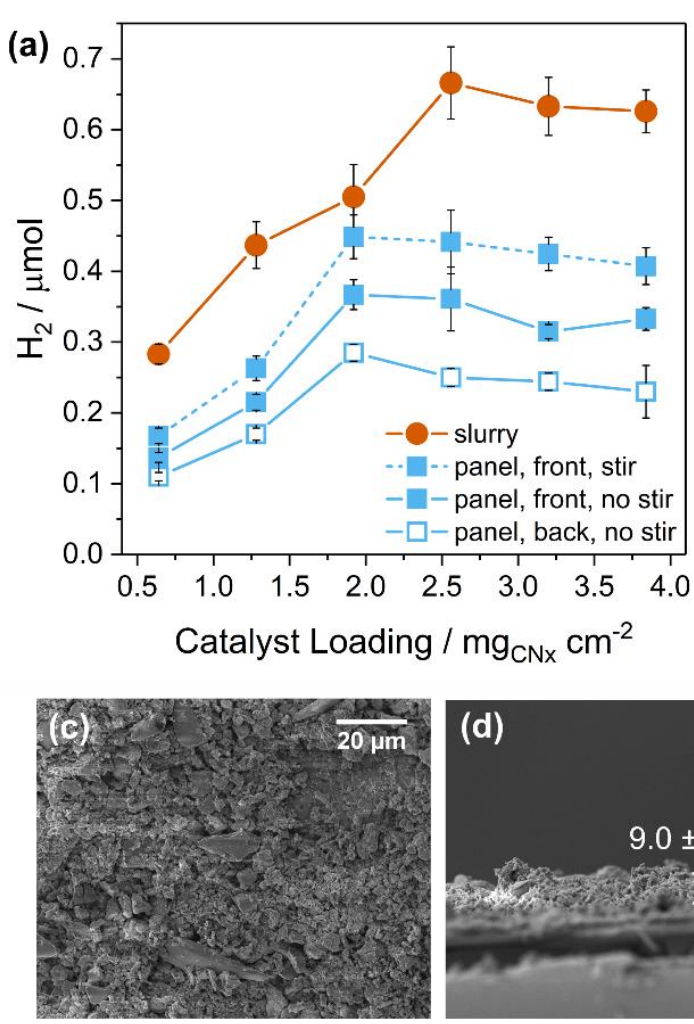

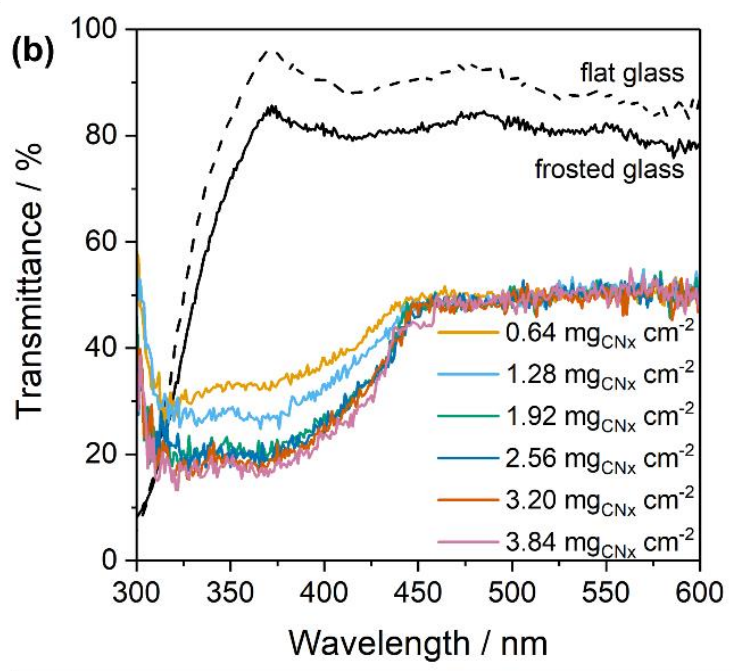

(e) Front irradiation

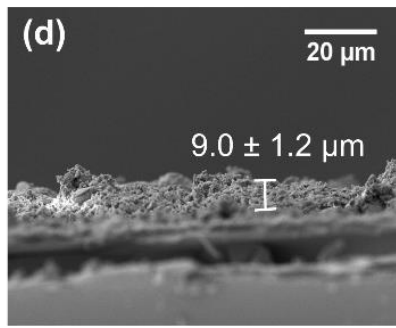

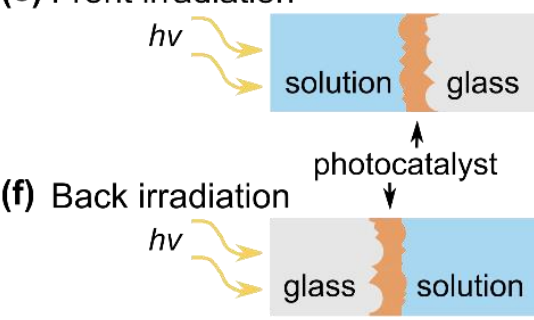

Figure 2. (a) Optimization of photocatalyst panel loading for $\mathrm{H}_{2}$ evolution. Conditions: $\mathrm{CN}_{\mathrm{x}} \mid \mathrm{Ni}_{2} \mathrm{P}$ as a slurry or deposited on frosted glass $\left(1 \mathrm{~cm}^{2}\right)$, ethylene glycol $(50 \mathrm{mg}), \mathrm{H}_{2} \mathrm{O}(1 \mathrm{~mL}$ for slurry, $2 \mathrm{~mL}$ for panel), irradiation $\left(100 \mathrm{~mW} \mathrm{~cm}^{-2}, 20 \mathrm{~h}, 25^{\circ} \mathrm{C}\right)$. (b) $\mathrm{UV}$-vis transmittance spectra of panels with different photocatalyst loadings. (c) Top-view and (d) side-view scanning electron microscopy images of an optimized $1.92 \mathrm{mg}_{\mathrm{CNx}} \mathrm{cm}^{-2}$ photocatalyst panel. Schematic diagrams of (e) front and (f) back irradiation configurations. 


\section{WILEY-VCH}

A $\mathrm{CN}_{\mathrm{x}} \mid \mathrm{Ni}_{2} \mathrm{P}$ loading of $1.92 \mathrm{mg} \mathrm{\textrm {cm } ^ { - 2 }}$ was selected as optimal, as it requires the lowest quantity of material to retain maximal $\mathrm{H}_{2}$ activity under various reactor configurations. Front irradiation, in which light shines through the reaction solution and onto the photocatalyst (Figure 2e), is the most common illumination mode for photocatalytic $\mathrm{H}_{2}$ evolution. In this configuration, the optimized $\mathrm{CN}_{\mathrm{x}} \mid \mathrm{Ni}_{2} \mathrm{P}$ panels produce $\sim 73 \%$ as much $\mathrm{H}_{2}\left(185 \pm 10 \mu \mathrm{mol}_{\mathrm{H}_{2}} \mathrm{~m}^{-2}\right.$ $\mathrm{h}^{-1}$ ) as the same quantity of photocatalyst in a slurry (Figure 2a), and reach an external quantum yield of $0.021 \pm 0.005 \%$ at $\lambda=430 \mathrm{~nm}$ (Table S5). If stirring at $600 \mathrm{rpm}$ is introduced with the optimized $\mathrm{CN}_{\mathrm{x}} \mid \mathrm{Ni}_{2} \mathrm{P}$ panels, the $\mathrm{H}_{2}$ yield $(0.45 \pm 0.03 \mu \mathrm{mol})$ becomes statistically equivalent to that of a corresponding slurry $(0.50 \pm 0.05 \mu \mathrm{mol})$, suggesting that the lower panel efficiency can likely be attributed to mass transport limitations (Figure 2a). Back irradiation, when light shines through the glass on which the photocatalyst is deposited (Figure 2f), is of particular interest for practical PR applications in which the depth and turbidity of the reaction solution compete with photocatalyst light absorption. ${ }^{[21]}$ It is therefore encouraging that $\mathrm{CN}_{\mathrm{x}} \mid \mathrm{Ni}_{2} \mathrm{P}$ panels under back irradiation have only a slightly lower $(\sim 20 \%) \mathrm{H}_{2}$ yield than front irradiation, due to light absorption by the frosted glass substrate (Figure 2a, Figure 2b).

The panel preparation procedure is also applicable to other photocatalysts: mesoporous (mpg) $\mathrm{CN}_{\mathrm{x}} \mid \mathrm{Ni}_{2} \mathrm{P}$ and cyanamide-functionalized $\mathrm{CN}_{\mathrm{x}} \mid \mathrm{Ni}_{2} \mathrm{P}$ panels have similar areal efficiencies to that of $\mathrm{CN}_{\mathrm{x}} \mid \mathrm{Ni}_{2} \mathrm{P}$, whereas $\mathrm{CN}_{\mathrm{x}} \mid \mathrm{Pt}$ performs $\sim 1.5$ times better (Table $\mathrm{S} 6$ ). $\mathrm{TiO}_{2} \mid \mathrm{Ni}_{2} \mathrm{P}$ panels produce up to $480 \pm 80 \mu \mathrm{mol}_{\mathrm{H}_{2}} \mathrm{~m}^{-2} \mathrm{~h}^{-1}$ from EG in $\mathrm{H}_{2} \mathrm{O}$, but fail to generate $\mathrm{H}_{2}$ without ultraviolet irradiation (Table S6). $\mathrm{CN}_{\mathrm{x}} \mid \mathrm{Ni}_{2} \mathrm{P}$ panels, in contrast, maintain $\sim 42 \%$ of their activity under visible light only radiation $(\lambda>400 \mathrm{~nm}$, Table $\mathrm{S} 3)$.

The stability of the $1.92 \mathrm{mg} \mathrm{cm}{ }^{-2} \mathrm{CN}_{\mathrm{x}} \mid \mathrm{Ni}_{2} \mathrm{P}$ panels was subsequently tested. Panels in $\mathrm{H}_{2} \mathrm{O}$ or $0.5 \mathrm{M}$ aq. $\mathrm{KOH}$ with EG were irradiated for 5 days either continuously or with recycling every $24 \mathrm{~h}$ (Table S7, Figure S4). Recycling involved removing the panels from the PR solution, gently washing by dipping in $\mathrm{H}_{2} \mathrm{O}$, drying under a $\mathrm{N}_{2}$ stream and then re-immersing 


\section{WILEY-VCH}

the panels in a fresh PR solution. Panel recyclability and long-term usability is dependent on the aqueous conditions. In $\mathrm{H}_{2} \mathrm{O}$, the $\mathrm{H}_{2}$ areal efficiency slowly decreases during continuous use (from 110 to $81 \mu \mathrm{mol}_{\mathrm{H}_{2}} \mathrm{~m}^{-2} \mathrm{~h}^{-1}$ over five days), and the efficiency halves after the fourth reuse cycle. FTIR spectroscopy shows that the fingerprint region of $\mathrm{CN}_{\mathrm{x}}$ remains unchanged after PR, indicating that the photocatalyst itself is robust (Figure S5). Instead, the decrease in efficiency can likely be attributed to $\mathrm{Ni}_{2} \mathrm{P}$ degradation, as ICP-OES shows that $26 \%$ of the cocatalyst $\mathrm{Ni}$ content leaches into the PR solution after five days (Table S1). It should nevertheless be noted that up to $60 \%$ of $\mathrm{Ni}$ was previously reported to leach from a $\mathrm{CN}_{\mathrm{x}} \mid \mathrm{Ni}_{2} \mathrm{P}$ slurry in $\mathrm{H}_{2} \mathrm{O}$ in the same time frame, ${ }^{[12]}$ suggesting either that immobilization enhances the durability of the photocatalyst or that only $\mathrm{Ni}_{2} \mathrm{P}$ on the panel surface (rather than in its bulk) is degraded.

Alkaline conditions have been shown to improve substrate solubility, particularly for synthetic polymers and complex biomass, and enhance $\mathrm{H}_{2}$ evolution activity during PR. ${ }^{[10,11,22]}$ Stability under these conditions is crucial for the application of photocatalyst panels to PR of real waste. In $0.5 \mathrm{M}$ aq. $\mathrm{KOH}$, the $\mathrm{CN}_{\mathrm{x}} \mid \mathrm{Ni}_{2} \mathrm{P}$ panels retain over $70 \%$ of their activity after four reuse cycles and show even smaller decreases in $\mathrm{H}_{2}$ evolution during continuous use (from 204 to $176 \mu \mathrm{mol}_{\mathrm{H}_{2}} \mathrm{~m}^{-2} \mathrm{~h}^{-1}$ ). Only $0.3 \%$ of Ni leaches into the PR solution after five days (Table S1), an effect that has been previously explained by the formation of a stabilizing $\mathrm{Ni}(\mathrm{OH})_{2}$ layer on $\mathrm{Ni}_{2} \mathrm{P}$ under alkaline conditions. ${ }^{[23,24]}$ Any efficiency losses are more likely attributable to abrasion of the panel, particularly after washing, as observed by scanning electron microscopy (SEM, Figure S6). The adsorption of organics on the photocatalyst surface may also play a role. $\mathrm{CN}_{\mathrm{x}} \mid \mathrm{Ni}_{2} \mathrm{P}$ panels thus have unique benefits crucial for scaling of $\mathrm{PR}$, including facile preparation, low cost, activity under visible light, and stability in alkaline solution. 


\section{WILEY-VCH}

\subsection{Photoreforming of waste with panels}

Having optimized and characterized the $\mathrm{CN}_{\mathrm{x}} \mid \mathrm{Ni}_{2} \mathrm{P}$ panels using a model substrate, the immobilized system was applied to PR of various solid waste streams (Figure 3a). All substrates were stirred in $0.5 \mathrm{M}$ aq. $\mathrm{KOH}$ at $80{ }^{\circ} \mathrm{C}$ overnight at a loading of $25 \mathrm{mg} \mathrm{mL}{ }^{-1}$ (concentration optimized for maximal $\mathrm{H}_{2}$ production); this simple pre-treatment has been previously reported to initiate waste breakdown and improve PR efficiency. ${ }^{[11,12]}$ Although higher concentrations of $\mathrm{KOH}$ solubilize up to $30 \%$ more substrate and increase $\mathrm{H}_{2}$ yields when used with a $\mathrm{CN}_{\mathrm{x}} \mid \mathrm{Ni}_{2} \mathrm{P}$ slurry (Table $\mathrm{S} 8$ ), they also rapidly degrade the photocatalyst panel adhesion and were therefore not utilized in this study. The pre-treated substrates were centrifuged and, if necessary, filtered to remove insoluble particles and then used for PR with $1 \mathrm{~cm}^{2} \mathrm{CN}_{\mathrm{x}} \mid \mathrm{Ni}_{2} \mathrm{P}$ panels as described previously (Figure 3b). PET powder, $\alpha$-cellulose (a component of biomass), and MSW were selected for in-depth study in order to examine the effect of reactor configuration on PR efficiency with different substrate transparencies. Pretreated PET solution is transparent ( $80 \%$ transmittance at $\lambda=400 \mathrm{~nm}), \alpha$-cellulose is semitransparent (16\% transmittance) and MSW is opaque (0\% transmittance, Figure S7). Note that any inorganic (non-photoreformable) components were removed from MSW by a sink-float separation technique prior to use in PR.

Small photocatalyst panels under back irradiation generate $156 \pm 15,31 \pm 3$, and $15 \pm 2$ $\mu_{\mathrm{mol}} \mathrm{H}_{2} \mathrm{~m}^{-2} \mathrm{~h}^{-1}$ during PR of PET, $\alpha$-cellulose and MSW, respectively (Figure 3a, Table S9). These values are comparable to, or higher than, slurries with equivalent $\mathrm{CN}_{\mathrm{x}} \mid \mathrm{Ni}_{2} \mathrm{P}$ loadings. The panels are versatile and can be applied to PR of other substrates, such as the biodegradable polymer polylactic acid with a rate of $264 \pm 13 \mu \mathrm{mol}_{\mathrm{H}_{2}} \mathrm{~m}^{-2} \mathrm{~h}^{-1}$, as well as at neutral $\mathrm{pH}$ (e.g. with soybean oil and $\alpha$-cellulose, Table S9). Furthermore, the PR oxidation chemistry is unchanged upon $\mathrm{CN}_{\mathrm{x}} \mid \mathrm{Ni}_{2} \mathrm{P}$ immobilization, as verified by ${ }^{1} \mathrm{H}$ - and ${ }^{13} \mathrm{C}$-nuclear magnetic resonance (NMR) spectroscopy of EG and $\alpha$-cellulose after five days of PR with photocatalyst 
slurries and panels (Figure S8). Over both immobilized and dispersed $\mathrm{CN}_{\mathrm{x}} \mid \mathrm{Ni}_{2} \mathrm{P}, \mathrm{EG}$ PR follows the previously reported trend of oxidation to glycolaldehyde, glyoxal, glycolate, glyoxylate, formate and carbonate. ${ }^{[11]}$ Similar quantities of formate are generated in both cases: $0.73 \mathrm{mM}$ and $0.88 \mathrm{mM}$ from the slurry and panel, respectively, as quantified by ${ }^{1} \mathrm{H}-\mathrm{NMR}$ spectroscopy. The end groups of $\alpha$-cellulose, meanwhile, are oxidized during PR to carboxylic acids, eventually generating formate $(0.37 \mathrm{mM}$ slurry and $0.21 \mathrm{mM}$ panel $)$ and carbonate. ${ }^{[25,26]}$

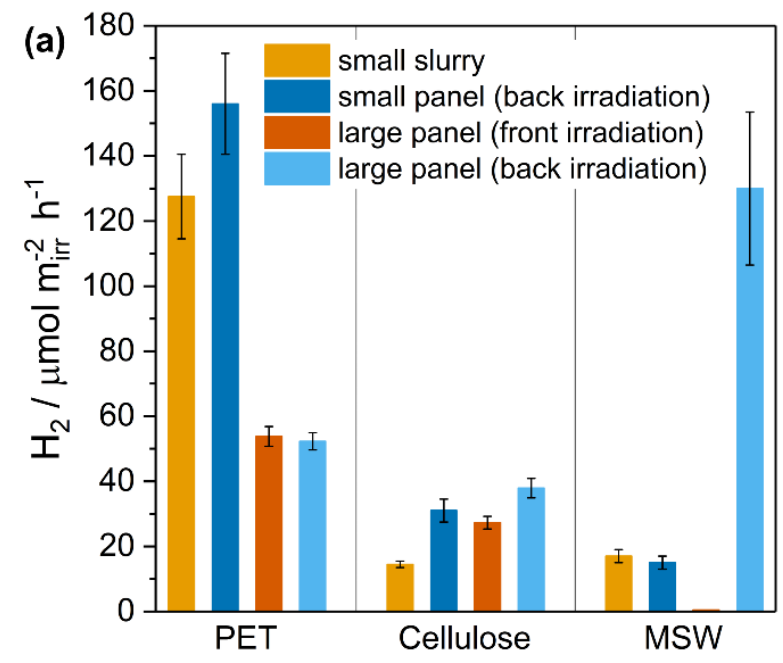

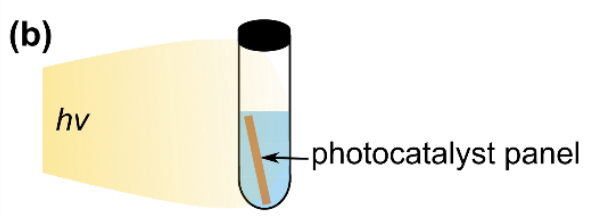

(c)

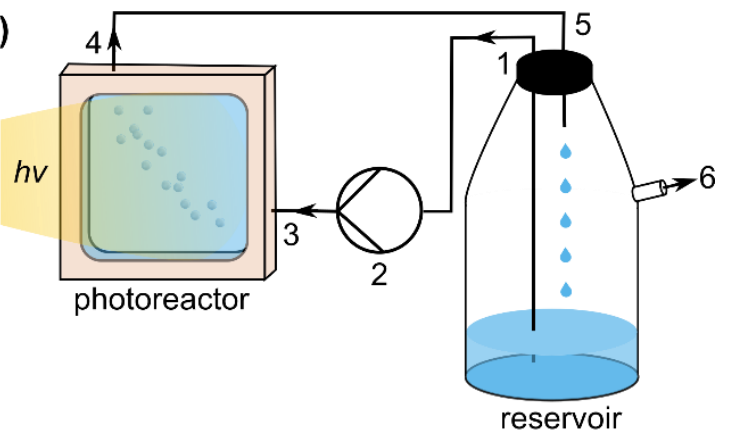

Figure 3. (a) Comparison of small-scale slurry, small-scale panels $\left(1 \mathrm{~cm}^{2}\right)$ and front and back irradiation configurations of large-scale panels $\left(25 \mathrm{~cm}^{2}\right)$ for photoreforming of polyethylene terephthalate (PET), $\alpha$-cellulose and municipal solid waste (MSW) substrate solutions. Conditions: $\mathrm{CN}_{\mathrm{x}} \mid \mathrm{Ni}_{2} \mathrm{P}\left(1.92 \mathrm{mg} \mathrm{cm}{ }^{-2}\right)$ dispersed as a slurry or deposited on frosted glass ( 1 and $25 \mathrm{~cm}^{2}$ for small- and large-scale experiments, respectively; stirring with slurry, no stirring with panels); substrate $\left(25 \mathrm{mg} \mathrm{mL}^{-1}\right) ; 0.5 \mathrm{M}$ aq. $\mathrm{KOH}(1$, 2 and $50 \mathrm{~mL}$ for small-scale slurry, small-scale panel and large-scale panel experiments, respectively); irradiation $\left(20 \mathrm{~h}, 100 \mathrm{~mW} \mathrm{~cm}{ }^{-2}, 25^{\circ} \mathrm{C}\right)$; flow rate $2 \mathrm{~mL} \mathrm{~min}^{-1}$ for large-scale setup. (b) Schematic diagram of small-scale panel experiments. (c) Schematic diagram of large-scale panel experiments in flow; the photoreforming solution is continuously pumped out of a reservoir (1) by a peristaltic pump (2) through the inlet (3) and outlet (4) of the photoreactor before returning to the reservoir (5). Evolved $\mathrm{H}_{2}$ is sampled from the reservoir outlet (6) and analyzed by gas chromatography.

PR of PET, $\alpha$-cellulose and MSW was next assessed in an up-scaled, custom-built flow reactor. This setup has three components: a reservoir, peristaltic pump and photoreactor (Figure 3c, Figure S9). The photoreactor was constructed from polyether ether ketone (PEEK) for high mechanical and chemical resistance, and has two $25 \mathrm{~cm}^{2}(2 \mathrm{~mm}$ thick) borosilicate 


\section{WILEY-VCH}

windows and a reactor depth of $1.2 \mathrm{~cm}$. Filtered pre-treated waste $(50 \mathrm{~mL})$ is circulated continuously between the reservoir and photoreactor, and evolved $\mathrm{H}_{2}$ is captured in the upward flow and sampled from an outlet in the reservoir. The flow rate was optimized at $2 \mathrm{~mL} \mathrm{~min}{ }^{-1}$ (Table S10), and flow pattern analysis confirms that the waste solution disperses across the entire photoreactor (Figure S10). Due to circulation between the (light) photoreactor and (dark) reservoir, reported rates utilize residence time within the photoreactor rather than total time. Initial experiments with this setup and triethanolamine as a sacrificial electron donor in $\mathrm{H}_{2} \mathrm{O}$ produced up to $750 \mu \mathrm{mol}_{\mathrm{H}_{2}} \mathrm{~m}^{-2} \mathrm{~h}^{-1}$ (Table S11), twelve times lower than a $1 \mathrm{~m}^{2}$ reactor of a similar setup that utilized mpg-CN ${ }_{\mathrm{x}}$ coupled with an expensive Pt co-catalyst (Table 1). ${ }^{[2]}$

PR with PET in flow generates statistically equivalent amounts of $\mathrm{H}_{2}$ under back and front irradiation due to the high transparency of the pre-treated PET solution (Figure 3a, Table $\mathrm{S} 12)$. However, there is a three-fold drop in efficiency between the 1 and $25 \mathrm{~cm}^{2}$ scales. PR with $\alpha$-cellulose, on the other hand, features similar areal efficiencies at both scales, as well as a relative $\mathrm{H}_{2}$ production increase of $40 \%$ between front and back irradiation. Finally, the rate of $\mathrm{H}_{2}$ generation from MSW under back irradiation is enhanced by 8-9 times on the larger versus smaller scale. The improvement in PR efficiency for less transparent substrates $(\alpha-$ cellulose and MSW) at larger scales can be at least partially attributed to reactor design: $1 \mathrm{~cm}^{2}$ $\mathrm{CN}_{\mathrm{x}} \mid \mathrm{Ni}_{2} \mathrm{P}$ panels rested against the side of a cylindrical photoreactor and thus a thin layer of waste solution was in front of the panel and partially obstructed incident light (Figure 3b), whereas the $25 \mathrm{~cm}^{2}$ panel was deposited directly onto the photoreactor window, hence eliminating this light absorption effect (Figure 3c). PR of PET, on the other hand, is not limited by solution transparency, and other effects introduced by scaling (e.g. mass transport challenges, irregularities in the larger photocatalyst panels, etc.) will therefore dominate and reduce overall $\mathrm{H}_{2}$ production in the $25 \mathrm{~cm}^{2}$ setup. Substrate-dependent kinetic barriers that are 


\section{WILEY-VCH}

affected by the use of batch versus flow conditions - such as the adsorption and reaction of certain oxidation intermediates on the immobilized photocatalyst - may also play a role.

These results highlight the importance of considering reactor configuration when designing an up-scaled photocatalytic process. For example, no $\mathrm{H}_{2}$ is produced from MSW with front irradiation, as the opacity of the waste solution prevents photons from reaching the photocatalyst panel. The MSW solution would need to be diluted by at least 100 times in order to achieve $50 \%$ transmittance to a photocatalyst panel under front irradiation (Figure S7), requiring $4000 \mathrm{~L}$ of $0.5 \mathrm{M}$ aq. $\mathrm{KOH}$ to process only $1 \mathrm{~kg}$ of waste, which is not feasible when considering the economic, sustainability and energy requirements of up-scaled PR. Back irradiation eliminates this issue, enhancing the feasibility of PR with real-world waste.

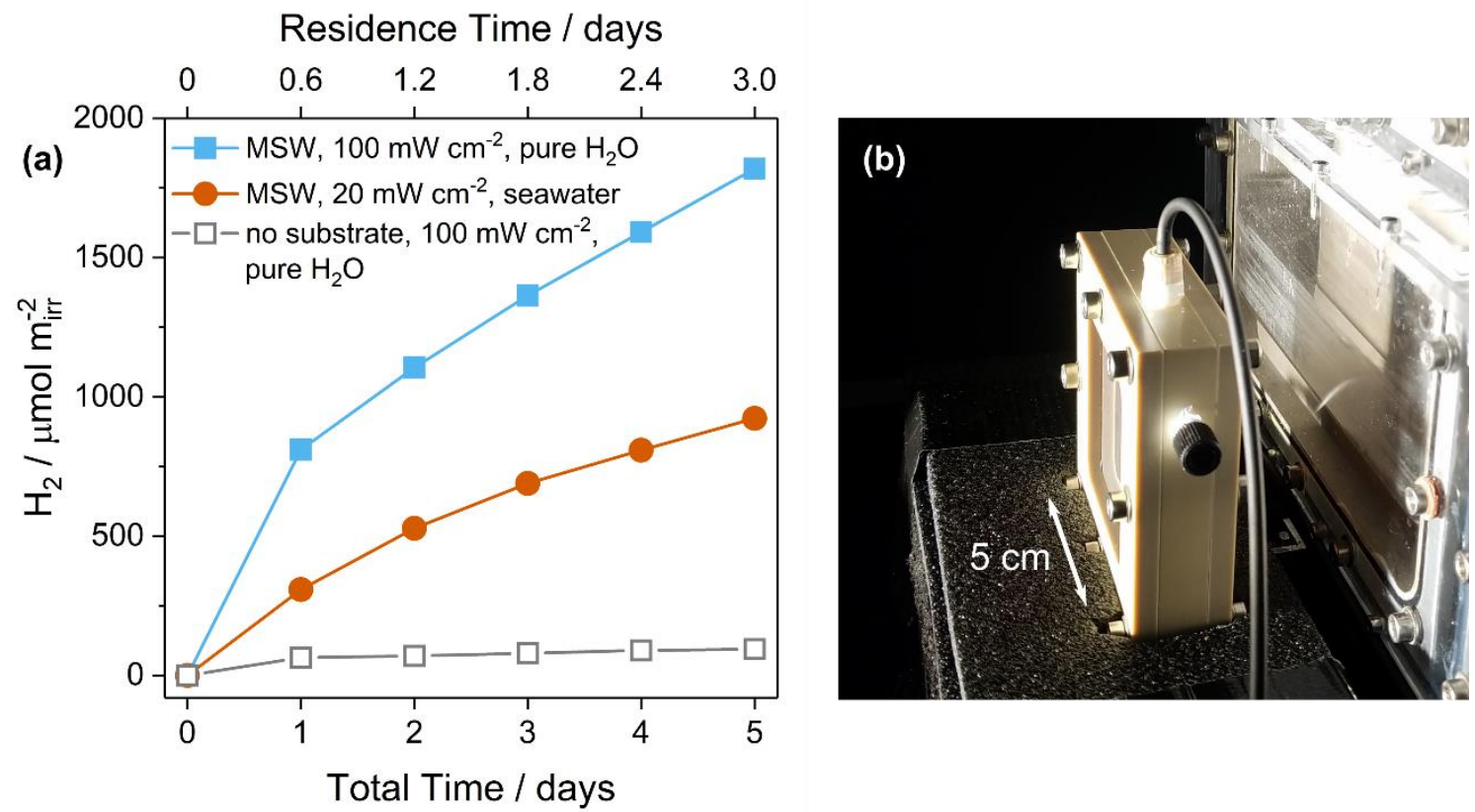

Figure 4. (a) Up-scaled long-term $\mathrm{H}_{2}$ evolution under ideal (100 $\mathrm{mW} \mathrm{cm} \mathrm{cm}^{-2}$, pure deionized water) and worst-case $\left(20 \mathrm{~mW} \mathrm{~cm}{ }^{-2}\right.$, seawater) conditions. Conditions: $\mathrm{CN}_{\mathrm{x}} \mid \mathrm{Ni}_{2} \mathrm{P}\left(1.92 \mathrm{mg} \mathrm{cm}^{-2}\right)$ deposited on frosted glass $\left(25 \mathrm{~cm}^{2}\right)$; municipal solid waste (MSW, $\left.25 \mathrm{mg} \mathrm{mL}^{-1}\right) ; 0.5 \mathrm{M}$ aq. $\mathrm{KOH}(50 \mathrm{~mL})$; irradiation (20 or $100 \mathrm{~mW} \mathrm{~cm}^{-2}$, ambient temperature); flow rate $2 \mathrm{~mL} \mathrm{~min}^{-1}$. Residence time refers to the period in which the solution inhabits the photoreactor, which is less than total time due to circulation between the (light) photoreactor and (dark) reservoir. (b) Photograph of the $25 \mathrm{~cm}^{2}$ photoreactor in use.

Finally, given the global water shortage ${ }^{[27]}$ and variability of solar radiation around the world (e.g. Europe at 6-26 $\mathrm{mW} \mathrm{cm}^{-2}$ on average, versus the $100 \mathrm{~mW} \mathrm{~cm}^{-2}$ used for standard 


\section{WILEY-VCH}

laboratory experiments), ${ }^{[28]}$ a PR system aimed at real-world application should ideally be operable in seawater and under reduced illumination. The operation limits of $\mathrm{PR}$ with $\mathrm{CN}_{\mathrm{x}} \mid \mathrm{Ni}_{2} \mathrm{P}$ panels were determined by exploring a series of seawater concentrations (0-100\%) and radiation intensities $\left(20-100 \mathrm{~mW} \mathrm{~cm}^{-2}\right)$ at the $1 \mathrm{~cm}^{2}$ scale with $\mathrm{EG}$ in $0.5 \mathrm{M} \mathrm{KOH}$ (Figure $\mathrm{S} 11$ ). Seawater results in a $35 \%$ decrease in $\mathrm{H}_{2}$ evolution in comparison to pure water, likely because of salinity-induced side reactions or kinetic effects, as well as reduced transparency due to calcium carbonate precipitation from seawater at high $\mathrm{pH}^{[29,30]}$ At $20 \mathrm{~mW} \mathrm{~cm}{ }^{-2}$, meanwhile, PR generates $116 \pm 6 \mu \mathrm{mol}_{\mathrm{H}_{2}} \mathrm{~m}^{-2} \mathrm{~h}^{-1}$ in comparison to $280 \pm 14 \mu \mathrm{mol}_{\mathrm{H}_{2}} \mathrm{~m}^{-2} \mathrm{~h}^{-1}$ at $100 \mathrm{~mW}$ $\mathrm{cm}^{-2} . \mathrm{H}_{2}$ evolution efficiency is proportional to the square root of the light intensity, which is expected for photocatalytic reactions in which the oxidation or reduction rate is slower than charge recombination. ${ }^{[31]}$ This suggests that $\mathrm{PR}$ with $\mathrm{CN}_{\mathrm{x}} \mid \mathrm{Ni}_{2} \mathrm{P}$ is limited not by the quantity of available photons, but rather by slow oxidation and/or reduction rates that facilitate charge recombination. The worst-case conditions $\left(100 \%\right.$ seawater and $\left.20 \mathrm{~mW} \mathrm{~cm}^{-2}\right)$ were then applied to up-scaled PR of MSW over the course of five days and compared to ideal conditions $(0 \%$ seawater, $100 \mathrm{~mW} \mathrm{~cm}{ }^{-2}$, Figure 4, Table S13). In the worst-case scenario, $25 \mathrm{~cm}^{2} \mathrm{CN}_{\mathrm{x}} \mid \mathrm{Ni}_{2} \mathrm{P}$ panels still produce up to $50 \%$ as much $\mathrm{H}_{2}$ as under ideal conditions, showcasing the versatility and real-world applicability of this PR system. This is a slightly higher value than expected from the small-scale experiments (38\% of efficiency retained under $100 \%$ seawater and $20 \mathrm{~mW}$ $\mathrm{cm}^{-2}$, Figure S11), and can likely be attributed to variations in the content of the MSW.

Overall PR efficiencies remain low in comparison to most other reported up-scaled photocatalyst panels for $\mathrm{H}_{2}$ generation (Table 1, see Table $\mathrm{S} 14$ for additional examples). This is due to photocatalyst selection (other panels use intrinsically more efficient materials based on noble metals) as well as the difficulty of reforming polymeric waste as opposed to utilizing a soluble and easily oxidizable sacrificial electron donor. Nevertheless, our $\mathrm{CN}_{\mathrm{x}} \mid \mathrm{Ni}_{2} \mathrm{P}$ waste PR system is already competitive with advanced solar water splitting panels made of complex 
photocatalysts such as $\mathrm{RhCrO}_{\mathrm{x}} / \mathrm{ZrO}_{2} /\left(\mathrm{LaMg}_{1 / 3} \mathrm{Ta}_{2 / 3} \mathrm{O}_{2} \mathrm{~N}\right) / \mathrm{Au} / \mathrm{BiVO}_{4}: \mathrm{Mo}$ or $\mathrm{Ga}-$ $\left(\mathrm{La}_{5} \mathrm{Ti}_{2} \mathrm{Cu}_{0.9} \mathrm{Ag}_{0.1} \mathrm{~S}_{5} \mathrm{O}_{7}\right) / \mathrm{Au} / \mathrm{LaTiO}_{2} \mathrm{~N}-\mathrm{CoO}_{\mathrm{x}} \cdot{ }^{[32,33]}$ Furthermore, PR over $\mathrm{CN}_{\mathrm{x}} \mid \mathrm{Ni}_{2} \mathrm{P}$ panels in flow offers numerous other benefits, including low cost (no precious metals), facile preparation, co-production of valuable organics, and use of waste as a sustainable and abundant feedstock for $\mathrm{H}_{2}$ production.

Table 1. Comparison of photoreforming of different substrates on $\mathrm{CN}_{\mathrm{x}} \mid \mathrm{Ni}_{2} \mathrm{P}$ panels to selected literature reports for water splitting (with or without a sacrificial electron donor) on photocatalyst panels. Unless stated otherwise in the "Other Conditions" column, samples were tested in pure $\mathrm{H}_{2} \mathrm{O}$ under simulated sunlight $\left(100 \mathrm{~mW} \mathrm{~cm}{ }^{-2}\right)$ at ambient temperature $\left(25^{\circ} \mathrm{C}\right)$ and pressure. $\mathrm{MSW}=$ municipal solid waste, PET $=$ polyethylene terephthalate, and TEOA $=$ triethanolamine.

\begin{tabular}{|c|c|c|c|c|c|c|}
\hline Photocatalyst & $\begin{array}{l}\text { Panel } \\
\text { Size }\end{array}$ & $\begin{array}{l}\text { Irradiation } \\
\text { Type }\end{array}$ & Substrate & $\begin{array}{l}\text { Other } \\
\text { Conditions }\end{array}$ & $\begin{array}{l}\text { Areal } \\
\text { Efficiency } \\
\left(\mu \mathrm{mol}_{\mathrm{H}_{2}}\right. \\
\left.\mathbf{m}^{-2} \mathbf{h}^{-1}\right)\end{array}$ & Ref. \\
\hline $\mathrm{CN}_{\mathrm{x}} \mid \mathrm{Ni}_{2} \mathrm{P}$ & $25 \mathrm{~cm}^{2}$ & $\begin{array}{l}\text { back } \\
\text { back } \\
\text { back } \\
\text { front }\end{array}$ & $\begin{array}{l}\text { Cellulose } \\
\text { MSW } \\
\text { PET } \\
\text { TEOA }\end{array}$ & $\begin{array}{l}0.5 \mathrm{M} \mathrm{KOH} \\
0.5 \mathrm{M} \mathrm{KOH} \\
0.5 \mathrm{M} \mathrm{KOH}\end{array}$ & $\begin{array}{l}38 \\
130 \\
52 \\
750 \\
\end{array}$ & $\begin{array}{l}\text { this } \\
\text { wor } \\
\mathrm{k}\end{array}$ \\
\hline $\mathrm{mpg}-\mathrm{CN}_{\mathrm{x}} \mid \mathrm{Pt}$ & $1 \mathrm{~m}^{2}$ & front & TEOA & natural sunlight & 9028 & [2] \\
\hline $\mathrm{RhCrO}_{\mathrm{x}} / \mathrm{SrTiO}_{3}: \mathrm{Al}$ & $1 \mathrm{~m}^{2}$ & front & none & natural sunlight & 42000 & [3] \\
\hline $\begin{array}{l}\mathrm{SrTiO}_{3}: \mathrm{La}, \mathrm{Rh} / \mathrm{Au} / \\
\mathrm{BiVO}_{4}: \mathrm{Mo}\end{array}$ & $7.5 \mathrm{~cm}^{2}$ & front & none & $10 \mathrm{kPa}, 58^{\circ} \mathrm{C}$ & 200000 & {$[16]$} \\
\hline $\begin{array}{l}\mathrm{RhCrO}_{\mathrm{x}} / \mathrm{ZrO}_{2} / \\
\left(\mathrm{LaMg}_{1 / 3} \mathrm{Ta}_{2 / 3} \mathrm{O}_{2} \mathrm{~N}\right) / \\
\mathrm{Au} / \mathrm{BiVO}_{4}: \mathrm{Mo}\end{array}$ & $9 \mathrm{~cm}^{2}$ & front & none & & 167 & {$[32]$} \\
\hline
\end{tabular}

\section{Conclusion}

We have reported the first example of a noble-metal-free photocatalyst panel for application to up-scaled photoreforming of solid waste in flow. $\mathrm{CN}_{\mathrm{x}} \mid \mathrm{Ni}_{2} \mathrm{P}$ panels were prepared by a facile drop-casting procedure, optimized for maximal $\mathrm{H}_{2}$ generation, and shown to produce $\mathrm{H}_{2}$ and simple organic molecules (e.g. formate) from a variety of plastic, biomass, food and mixed waste with rates comparable to corresponding photocatalyst slurries. A larger reactor $\left(25 \mathrm{~cm}^{2}\right)$ with continuous circulation was designed and used to generate $\mathrm{H}_{2}$ under both ideal and worstcase (seawater, reduced sunlight) scenarios. The effect of different irradiation configurations 


\section{WILEY-VCH}

on $\mathrm{H}_{2}$ yield was also investigated and shown to be crucial for enabling PR with turbid waste. The development of low-cost $\mathrm{CN}_{\mathrm{x}} \mid \mathrm{Ni}_{2} \mathrm{P}$ panels solves several photoreforming scaling challenges - including catalyst recycling, obstructive light absorption by the waste solution, and use of large quantities of water - and brings this unique technology one step closer to real world application in the waste and energy sectors. Future work should build upon this proofof-concept PR panel system by developing more active photocatalysts, enhancing sheet stability, improving waste solubility, and pursuing further up-scaling.

\section{Experimental Section}

Reagents. $\alpha$-Cellulose, chloroplatinic acid (8 wt $\%$ in $\mathrm{H}_{2} \mathrm{O}$ ), ethylene glycol, $\mathrm{D}_{2} \mathrm{O}$, ethylene glycol, $\mathrm{KOH}$ (semiconductor grade), melamine, and nafion (5\% in lower aliphatic alcohols and $\mathrm{H}_{2} \mathrm{O}$, contains $15-20 \% \mathrm{H}_{2} \mathrm{O}$ ) were purchased from Sigma-Aldrich. Polyethylene terephthalate (powder, $300 \mu \mathrm{m}$ ) and polylactic acid (pellets, $3 \mathrm{~mm}$ ) were obtained from Goodfellow Cambridge Ltd. Polylactic acid pellets were frozen in liquid $\mathrm{N}_{2}$ and then ground in a coffee grinder to powder prior to use. Artificial seawater, $\mathrm{NaOD}$ (40 wt \% in $\mathrm{D}_{2} \mathrm{O}$ ), nickel(II) chloride hexahydrate, sodium hypophosphite monohydrate and soybean oil were purchased from Fisher Scientific. $\mathrm{TiO}_{2} \mathrm{P} 25$ nanoparticles were received from Evonik. Municipal solid waste (middle fraction of a sink-float separation technique) was provided by the University of Leoben, Austria. Frosted borosilicate glass (one side) was obtained from Apex Optical Services.

Photocatalyst synthesis. Unfunctionalized carbon nitride $\left(\mathrm{CN}_{\mathrm{x}}\right)$ was prepared by heating melamine to $550{ }^{\circ} \mathrm{C}$ for $3 \mathrm{~h}$ (ramp rate $1{ }^{\circ} \mathrm{C} \min ^{-1}$ ) under air according to a literature procedure. ${ }^{[34]} \mathrm{CN}_{\mathrm{x}} \mid \mathrm{Ni}_{2} \mathrm{P}$ was synthesized as reported previously: ${ }^{[11]}$ in brief, $\mathrm{CN}_{\mathrm{x}}$, nickel(II) chloride hexahydrate and sodium hypophosphite monohydrate were combined in water, dried and subsequently annealed under $\operatorname{Ar}$ at $200{ }^{\circ} \mathrm{C}$ for $1 \mathrm{~h}\left(\operatorname{ramp}\right.$ rate $\left.5^{\circ} \mathrm{C} \min ^{-1}\right)$.

Photocatalyst panel preparation. Frosted glass $(0.5 \times 2 \mathrm{~cm}$ for small-scale panels, or $5 \times$ $5 \mathrm{~cm}$ for large-scale panels) was cleaned by sonication with isopropyl alcohol and ethanol for 


\section{WILEY-VCH}

15 min each, followed by drying under a $\mathrm{N}_{2}$ stream. $\mathrm{CN}_{\mathrm{x}} \mid \mathrm{Ni}_{2} \mathrm{P}$ was dispersed in ethanol (20 mg $\mathrm{mL}^{-1}$ ) by ultrasonication (10 min, pulses of $30 \mathrm{~s}$ at $100 \%$ amplitude followed by $5 \mathrm{~s}$ pauses), and $1 \mathrm{vol} \%$ nafion solution was added to the resulting mixture. $16 \mu \mathrm{L} \mathrm{cm}{ }^{-2}$ of the dispersion was drop-cast onto clean frosted glass and allowed to dry at ambient temperature (typically 2$10 \mathrm{~min}$ ) before the addition of subsequent layers. The prepared photocatalyst panels were then annealed at $80{ }^{\circ} \mathrm{C}$ overnight in air.

Physical characterization. UV-vis spectra were recorded on a Varian Cary $60 \mathrm{UV}$-vis spectrophotometer equipped with a diffuse reflectance accessary. SEM was conducted on a TESCAN MIRA3 FEG-SEM; samples were sputter-coated with a $10 \mathrm{~nm}$ layer of Pt prior to microscopy. FTIR spectra were collected on a Thermo Scientific Nicolet iS50 FTIR spectrometer (ATR mode). ICP-OES measurements were completed by the Microanalysis Service at the University of Cambridge (Department of Chemistry) on a Thermo Scientific iCAP 700 spectrometer; samples were prepared in a $2 \%$ nitric acid matrix.

NMR spectroscopy. ${ }^{1} \mathrm{H}$ - and ${ }^{13} \mathrm{C}-\mathrm{NMR}$ spectra were collected on either a 400 or $500 \mathrm{MHz}$ Bruker Avance spectrometer equipped with a smart probe. For peak determination, samples were compared to and/or spiked with pure authentic molecules. For quantitative ${ }^{1} \mathrm{H}-\mathrm{NMR}$ spectroscopy, samples were spiked with a known quantity of a standard solution $\left(50 \mathrm{mg} \mathrm{mL}^{-1}\right.$ potassium hydrogen phthalate in $\left.\mathrm{D}_{2} \mathrm{O}\right)$ after PR. The quantity of analyte $\left(m_{\text {analyte }}\right)$ was determined with Eq. 1:

$$
m_{\text {analyte }}=\frac{I_{\text {analyte }}}{I_{\text {standard }}} \cdot \frac{N_{\text {standard }}}{N_{\text {analyte }}} \cdot \frac{M_{\text {analyte }}}{M_{\text {standard }}} \cdot m_{\text {standard }}
$$

Where: $I_{\text {analyte }}$ - integral of the analyte peak,

$N_{\text {analyte }}$ - number of protons corresponding to the analyte peak,

$M_{\text {analyte }}$ - molar mass of the analyte,

$m_{\text {standard }}-$ known mass of the standard in the sample. 


\section{WILEY-VCH}

Substrate pre-treatment. Following a reported procedure, ${ }^{[11,22]}$ substrates $\left(25 \mathrm{mg} \mathrm{mL}{ }^{-1}\right)$ were soaked in $0.5 \mathrm{M}$ aq. $\mathrm{KOH}$ or $\mathrm{H}_{2} \mathrm{O}$ at $80{ }^{\circ} \mathrm{C}$ overnight with stirring at $500 \mathrm{rpm}$ in air. The mixture was centrifuged and, if necessary, filtered through a syringe filter to remove insoluble components prior to use in catalysis.

Small-scale photocatalytic generation of $\mathrm{H}_{2}$. Photocatalyst powder (dispersed by a previously reported ultrasonication procedure $)^{[26]}$ or a photocatalyst panel was added to a cylindrical Pyrex photoreactor tube ( $1 \mathrm{~cm}$ diameter, internal volume $7.91 \mathrm{~mL}$ ) containing $\mathrm{H}_{2} \mathrm{O}$ or aqueous $\mathrm{KOH}(0.5 \mathrm{M})$ solution ( $1 \mathrm{~mL}$ for slurry, $2 \mathrm{~mL}$ for panel) and the substrate of interest (50 mg). The samples were purged with $\mathrm{N}_{2}$ (containing $2 \% \mathrm{CH}_{4}$ for gas chromatographic analysis) at ambient pressure for $10 \mathrm{~min}$ and then irradiated by a solar light simulator (100 $\mathrm{mW}$ $\mathrm{cm}^{-2}$, LOT-Quantum Design) at $25^{\circ} \mathrm{C}$. Stirring (600 rpm) was only utilized for slurry samples. $\mathrm{H}_{2}$ was monitored by periodically analyzing aliquots of the reactor headspace ( $\left.50 \mu \mathrm{L}\right)$ by gas chromatography (GC, see below).

Large-scale photocatalytic generation of $\mathrm{H}_{2}$. A reservoir $(500 \mathrm{~mL})$ was filled with a substrate mixture $\left(50 \mathrm{~mL}, 25 \mathrm{mg} \mathrm{mL}^{-1}\right)$ and connected to the peristaltic pump and photoreactor (internal volume $5 \times 5 \times 1.2 \mathrm{~cm}, 30 \mathrm{~mL}$ ) by Viton tubing (inner diameter $1.6 \mathrm{~mm}$, see Figure S9 for setup). While continuously circulating the mixture between the reservoir and photoreactor at a high flow rate $\left(10-20 \mathrm{~mL} \mathrm{~min}^{-1}\right)$, the reservoir was purged with $\mathrm{N}_{2}$ (containing $2 \% \mathrm{CH}_{4}$ for $\mathrm{GC}$ analysis) at ambient pressure for $1 \mathrm{~h}$. The photoreactor was then irradiated by a solar light simulator (100 $\mathrm{mW} \mathrm{cm}{ }^{-2}$, LOT-Quantum Design) under a flow rate of $2 \mathrm{~mL} \mathrm{~min}^{-1}$. $\mathrm{H}_{2}$ was monitored by periodically analyzing aliquots of the reservoir headspace $(50 \mu \mathrm{L})$ by GC.

Gas analysis. The accumulation of $\mathrm{H}_{2}$ was measured with a Shimadzu Tracera GC-2010 Plus gas chromatograph equipped with a Hayesep D precolumn and RT-Molsieve 5A main column using $\mathrm{He}$ as the carrier gas. Methane $\left(2 \% \mathrm{CH}_{4}\right.$ in $\left.\mathrm{N}_{2}\right)$ was used as an internal standard after calibration with different mixtures of known amounts of $\mathrm{H}_{2} / \mathrm{N}_{2} / \mathrm{CH}_{4}$. 


\section{WILEY-VCH}

Treatment of data. Analytical measurements were performed in triplicate for small-scale samples and duplicate for large-scale samples, unless otherwise stated, and are given as the unweighted mean \pm standard deviation $(\sigma)$. Measurements are typically listed as areal efficiency $\left(\mu \mathrm{mol}_{\mathrm{H}_{2}} \mathrm{~m}^{-2}\right.$ or $\left.\mu \mathrm{mol}_{\mathrm{H}_{2}} \mathrm{~m}^{-2} \mathrm{~h}^{-1}\right)$, yield per weight of substrate $\left(\mu \mathrm{mol}_{\mathrm{H}_{2}} \mathrm{~g}_{\text {sub }}{ }^{-1}\right.$ ) and activity per weight of catalyst $\left(\mu_{\mathrm{mol}_{\mathrm{H}}} \mathrm{g}_{\mathrm{cat}}^{-1} \mathrm{~h}^{-1}\right), \sigma$ was calculated using Eq. 2.

$$
\sigma=\sqrt{\frac{\sum(x-\bar{x})^{2}}{n-1}}
$$

Where: $n$ - number of repeated measurements,

$x$ - value of a single measurement,

$\bar{x}$ - unweighted mean of the measurements.

$\sigma$ was increased to $5 \%$ of $\bar{x}$ in the event that the calculated $\sigma$ was below this threshold.

External quantum yield (EQY) determination. A photocatalyst panel $\left(1.92 \mathrm{mg}_{\mathrm{CNx}} \mathrm{mL}^{-1}\right)$, EG (50 mg) and $\mathrm{H}_{2} \mathrm{O}(2 \mathrm{~mL})$ were added to a quartz cuvette (path length $1 \mathrm{~cm}$ ), which was then sealed with a rubber septum. The sample was purged with $\mathrm{N}_{2}$ containing $2 \% \mathrm{CH}_{4}$ for 10 min and subsequently irradiated by a Xe lamp (LOT LSH302) fitted with a monochromator (LOT MSH300) focused at a single wavelength of $\lambda=430 \mathrm{~nm}$ (accurate to a full-width at halfmaximum of $5 \mathrm{~nm}$ ). The light intensity was adjusted to $\sim 1000 \mu \mathrm{W} \mathrm{cm}{ }^{-2}$ across a sample area of $0.28 \mathrm{~cm}^{2}$, as measured with a power meter (ILT 1400, International Light Technologies). The evolved headspace gas was analyzed by GC and the EQY (\%) calculated using Eq. 3.

$$
\operatorname{EQY}(\%)=100 \times \frac{2 n_{\mathrm{H}_{2}} N_{\mathrm{A}} h c}{t_{\mathrm{irr}} \lambda I A}
$$

Where: $n_{\mathrm{H}_{2}}-$ amount of $\mathrm{H}_{2}$ generated (mol),

$$
\begin{aligned}
& N_{\mathrm{A}}-\text { Avogadro's constant }\left(\mathrm{mol}^{-1}\right), \\
& h \text { - Planck's constant }(\mathrm{J} \mathrm{s}), \\
& c-\text { speed of light }\left(\mathrm{m} \mathrm{s}^{-1}\right),
\end{aligned}
$$


$t_{\text {irr }}-$ irradiation time (s),

$\lambda$ - wavelength $(\mathrm{m})$,

$I$ - light intensity $\left(\mathrm{W} \mathrm{m}^{-2}\right)$,

$A$ - irradiated area $\left(\mathrm{m}^{2}\right)$.

\section{Supporting Information}

Supporting Information is available from the Wiley Online Library. Data related to this publication are available at the University of Cambridge data repository: (doi to be added upon manuscript acceptance).

\section{Conflicts of Interest}

A patent application covering carbon-based photocatalysts for photoreforming has been filed by Cambridge Enterprise (PCT WO2019/229255).

\section{Acknowledgements}

This work was supported by the Cambridge Creative Circular Plastics Centre (EP/S025308/1), EPSRC (NanoDTC, EP/L015978/1 and EP/S022953), Endeavour Scholarship Scheme, Austrian Science Fund (Schrödinger Scholarship J-4381), and the OMV Group. We thank Dr. Qian Wang and Dr. Stuart Linley for useful discussions.

\section{References}

[1] International Energy Agency, The Future of Hydrogen: Seizing Today's Opportunities, 2019.

[2] M. Schröder, K. Kailasam, J. Borgmeyer, M. Neumann, A. Thomas, R. Schomäcker, M. Schwarze, Energy Technol. 2015, 3, 1014.

[3] Y. Goto, T. Hisatomi, Q. Wang, T. Higashi, K. Ishikiriyama, T. Maeda, Y. Sakata, S. Okunaka, H. Tokudome, M. Katayama, S. Akiyama, H. Nishiyama, Y. Inoue, T. Takewaki, T. Setoyama, T. Minegishi, T. Takata, T. Yamada, K. Domen, Joule 2018, 2, 509.

[4] D. Jing, H. Liu, X. Zhang, L. Zhao, L. Guo, Energy Convers. Manag. 2009, 50, 2919.

[5] M. I. Maldonado, A. López-Martín, G. Colón, J. Peral, J. I. Martínez-Costa, S. Malato, Appl. Catal. B Environ. 2018, 229, 15.

[6] Q. Wei, Y. Yang, J. Hou, H. Liu, F. Cao, L. Zhao, Sol. Energy 2017, 153, 215. 
[7] B. Xia, Y. Zhang, B. Shi, J. Ran, K. Davey, S. Qiao, Small Methods 2020, 4, 2000063.

[8] A. V. Puga, Coord. Chem. Rev. 2016, 315, 1.

[9] M. F. Kuehnel, E. Reisner, Angew. Chemie Int. Ed. 2018, 57, 3290.

[10] T. Kawai, T. Sakata, Chem. Lett. 1981, 81.

[11] T. Uekert, H. Kasap, E. Reisner, J. Am. Chem. Soc. 2019, 141, 15201.

[12] T. Uekert, F. Dorchies, C. Pichler, E. Reisner, Green Chem. 2020, 22, 3262.

[13] R. J. Braham, A. T. Harris, Ind. Eng. Chem. Res. 2009, 48, 8890.

[14] A. Xiong, G. Ma, K. Maeda, T. Takata, T. Hisatomi, T. Setoyama, J. Kubota, K. Domen, Catal. Sci. Technol. 2014, 4, 325.

[15] Z. Pan, T. Hisatomi, Q. Wang, M. Nakabayashi, N. Shibata, C. Pan, T. Takata, K. Domen, Appl. Catal. A Gen. 2016, 521, 26.

[16] Q. Wang, T. Hisatomi, Q. Jia, H. Tokudome, M. Zhong, C. Wang, Z. Pan, T. Takata, M. Nakabayashi, N. Shibata, Y. Li, I. D. Sharp, A. Kudo, T. Yamada, K. Domen, Nat. Mater. 2016, 15,611 .

[17] Q. Wang, S. Okunaka, H. Tokudome, T. Hisatomi, M. Nakabayashi, N. Shibata, T. Yamada, K. Domen, Joule 2018, 2, 2667.

[18] H. Park, W. Choi, J. Phys. Chem. B 2005, 109, 11667.

[19] R. Geyer, J. R. Jambeck, K. L. Law, Sci. Adv. 2017, 3, e1700782.

[20] L. Hanssen, S. Kaplan, SPIE 1998, 3425, 28.

[21] M. Vezzoli, T. Farrell, A. Baker, S. Psaltis, W. N. Martens, J. M. Bell, Chem. Eng. J. 2013, 234, 57.

[22] T. Uekert, M. F. Kuehnel, D. W. Wakerley, E. Reisner, Energy Environ. Sci. 2018, 11, 2853.

[23] N. Danilovic, R. Subbaraman, D. Strmcnik, K.-C. Chang, A. P. Paulikas, V. R. Stamenkovic, N. M. Markovic, Angew. Chem. Int. Ed. 2012, 51, 12495.

[24] Z. Zhou, L. Wei, Y. Wang, H. E. Karahan, Z. Chen, Y. Lei, X. Chen, S. Zhai, X. Liao, Y. Chen, J. Mater. Chem. A 2017, 5, 20390.

[25] D. W. Wakerley, M. F. Kuehnel, K. L. Orchard, K. H. Ly, T. E. Rosser, E. Reisner, Nat. Energy 2017, 2, 17021.

[26] H. Kasap, D. S. Achilleos, A. Huang, E. Reisner, J. Am. Chem. Soc. 2018, 140, 11604.

[27] United Nations, Sustainable Development Goal 6: Synthesis Report on Water and Sanitation, New York, 2018.

[28] U. Pfeifroth, A. Sanchez-Lorenzo, V. Manara, J. Trentmann, R. Hollmann, J. Geophys. Res. Atmos. 2018, 123, 1735.

[29] K. E. Chave, E. Suess, Limnol. Oceanogr. 1970, 15, 633.

[30] J. Zhang, W. Hu, S. Cao, L. Piao, Nano Res. 2020, 13, 2313.

[31] Y. Nosaka, A. Y. Nosaka, J. Phys. Chem. C 2018, 122, 28748.

[32] Z. Pan, T. Hisatomi, Q. Wang, S. Chen, M. Nakabayashi, N. Shibata, C. Pan, T. Takata, M. 


\section{WILEY-VCH}

Katayama, T. Minegishi, A. Kudo, K. Domen, ACS Catal. 2016, 6, 7188.

[33] T. Hisatomi, T. Yamamoto, Q. Wang, T. Nakanishi, T. Higashi, M. Katayama, T. Minegishi, K. Domen, Catal. Sci. Technol. 2018, 8, 3918.

[34] J. Liu, Y. Liu, N. Liu, Y. Han, X. Zhang, H. Huang, Y. Lifshitz, S.-T. Lee, J. Zhong, Z. Kang, Science. 2015, 347, 970. 


\section{WILEY-VCH}

T. Uekert, M. A. Bajada, T. Schubert, C. M. Pichler and E. Reisner

Scalable photocatalyst panels for photoreforming of plastic, biomass and mixed waste in flow

Carbon nitride/nickel phosphide photocatalyst panels are prepared by a simple drop-casting procedure and used to produce hydrogen fuel from a variety of plastic, biomass, food and mixed waste in an upscaled flow reactor.

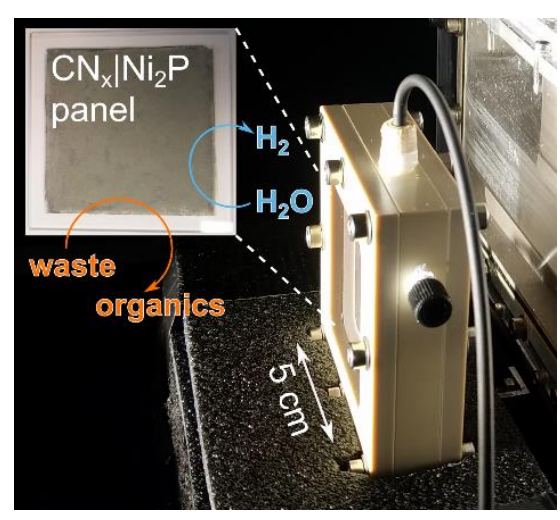

